\title{
PERFIL E AVALIAÇÃO DOS PARTICIPANTES DE UM CURSO DE FORMAÇÃO CONTINUADA EM PRÁTICAS EDUCACIONAIS INCLUSIVAS NA MODALIDADE A DISTÂNCIA*
}

\section{PROFILE AND EVALUATION OF PARTICIPANTS IN DISTANCE LEARNING CONTINUING EDUCATION COURSES ABOUT INCLUSIVE PRACTICES IN EDUCATION}

\author{
Vera Lúcia Messias Fialho Capellini** \\ Olga Maria Piazentin Rolim Rodrigues*** \\ Tania Gracy do Valle $e^{* * * *}$ \\ Lígia Ebner Melchiori ${ }^{* * * * *}$ \\ Eliana Marques Zanata****** \\ Lucia Pereira Leite \\ Rita Melissa Lepre ${ }^{* * * * * * * *}$
}

\begin{abstract}
Resumo
Este artigo analisa aspectos relacionados a um curso de formação continuada sobre práticas em Educação Especial e Inclusiva na área de Deficiência Mental, oferecido a professores de 20 (vinte) turmas inscritas pelo Ministério da Educação, de diferentes regiões do Brasil, com 180 (cento e oitenta) horas de duração, por meio de EaD. A pesquisa envolveu a descrição do perfil dos cursistas, uma análise da avaliação do curso realizada pelos cursistas e a das causas da evasão ocorrida no curso. Os resultados indicaram que os participantes, na sua maioria, avaliaram o curso positivamente em todos os aspectos solicitados. Os motivos mais frequentes para a evasão referiram-se às limitações dos cursistas, como a dificuldade em cumprir os prazos, motivos pessoais e inabilidade em usar computador. Concluiu-se que a Educação a Distância mostra-se como ferramenta relevante para aquisição de conhecimentos sobre a prática pedagógica inclusiva.
\end{abstract}

Palavras-chave: Ensino a Distância. Educação Inclusiva. Formação continuada.

\begin{abstract}
This article analyses aspects related to a continuing education course about Inclusive and Special Education in the area of Mental Disabilities offered to 20 (twenty) groups of teachers by the Ministry of Education. The Distance Course was offered in different regions of Brazil with a 180 (a hundred and eighty) hours workload. The research included the profile of the participants, an evaluation of the course by the participants and the analysis of the dropout causes. The aspects of the course under evaluation received a positive evaluation by most of the participants. The most frequent reason for the dropout rates include participants' limitations in terms of meeting deadlines, personal reasons and difficulties in using computers. It was concluded that Distance Education seems to be a relevant tool for the acquisition of knowledge about inclusive practice.
\end{abstract}

Keywords: Distance Learning. Inclusive Education. Continuing Education.

\footnotetext{
* Financiamento: MEC/FNDE/SEESP.

** Professora doutora da Universidade Estadual Paulista Júlio de Mesquita Filho, campus de Bauru. E-mail: verinha@fc.unesp.br

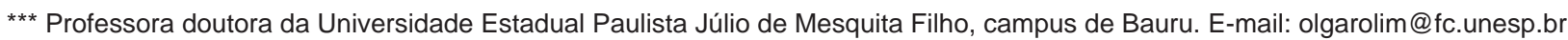

**** Professora doutora da Universidade Estadual Paulista Júlio de Mesquita Filho, campus de Bauru. E-mail: tgvalle@uol.com.br

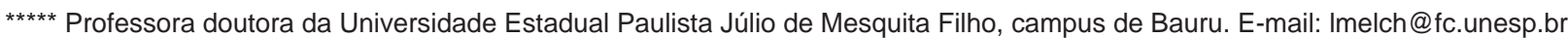

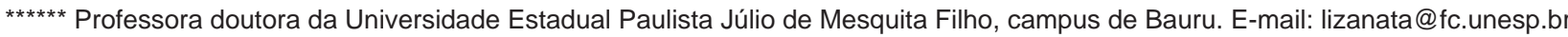

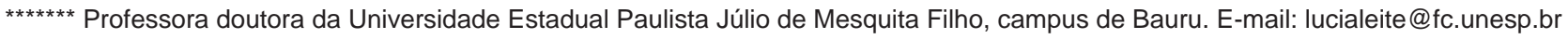




\section{Introdução}

Os cursos de Educação a Distância (EaD) têm sido oferecidos por intermédio do Projeto Universidade Aberta do Brasil (UAB), criado pelo Ministério da Educação (MEC), em 2005, no âmbito do Fórum das Estatais pela Educação, para articular e integrar um sistema nacional de Educação Superior a Distância, em caráter experimental, com a finalidade de sistematizar ações, programas, projetos e atividades pertencentes às políticas públicas, voltadas para ampliação e interiorização da oferta do Ensino Superior gratuito e de qualidade no Brasil.

Para ser aluno de cursos de Educação a Distância, é necessário que o pretendente tenha: condições de acesso ao computador, compatíveis às necessidades do curso; autonomia, para questionar e buscar respostas para seus questionamentos, isto é, exercitar o aprender sozinho, persistência e interesse pelos estudos. O aprender deve constituirse na finalidade prioritária para quem se propõe a estudar a distância. Aprender não significa apenas memorizar um livro ou alguns "pontos" com o fim de lembrar-se deles para a próxima avaliação (BARROS et al., 2008); a aprendizagem deve estar fundamentada em respeitável referencial teórico de diferentes campos de conhecimentos. O processo de aprendizagem exige esforço e motivação, então é necessário, primeiramente, compreender o que se deseja aprender e, em seguida, apropriar-se das novas ideias que surgem na mente, ligando-as às já existentes, construindo ou produzindo, assim, novos saberes.

A Educação a Distância é uma forma de tecnologia educacional em que o professor exerce um papel diferente. (FROMM NETTO, 1998; FIDALGO; MACHADO, 2000). Valente (2003) ressalta que, nesse contexto, o professor deixa de ser o "entregador" de informação para exercer o papel de facilitador do processo de aprendizagem. $\mathrm{O}$ aluno deixa de ser passivo, receptáculo das informações, para ser ativo aprendiz, construtor do seu conhecimento. Portanto, a ênfase da Educação não recai na memorização da informação transmitida pelo professor, mas na construção do conhecimento realizada pelo aluno, de maneira significativa, sendo o professor o facilitador desse processo.

A EaD tem sido uma experiência positiva na formação continuada de diferentes níveis de alunos. No entanto - como qualquer outra modalidade de ensino/educação -, apresenta limites e possibilidades. Em se tratando dos limites, pode-se destacar, entre outras, as causas elencadas por Coelho (2002) para que parte dos alunos se evada: a) ausência da tradicional relação face a face professor-estudante, o que pode gerar falta de empatia, de afetividade, deixando os alunos menos à vontade para buscar esclarecer suas dúvidas; b) inabilidade no uso da internet, o que acarreta dificuldades em receber e enviar e-mails, participar de chats, discutir suas ideias nos fóruns e sugerir links no intuito de apropriar-se de maior número de informações sobre o tema em discussão.

Além de Coelho (2002), outros autores apresentam os resultados de suas pesquisas. Shannon e Bylsma (2006), por exemplo, enumeram para a evasão fatores relacionados com a vida pessoal do estudante, em que entram aspectos como: família, questões socioeconômicas e realização acadêmica insuficiente.

Já os estudos de Workman e Sternard (1996) salientam que, dentre os fatores que levam o aluno à desistência, podem ser apontados: falta de consistência e clareza sobre objetivos, políticas e procedimentos relacionados ao curso; falta de automotivação e ausência de integração social no contato midiático.

Entretanto, para minimizar esses limites, podem ser criadas estratégias com a finalidade de se garantir a permanência dos estudantes nos cursos oferecidos em EaD. De acordo com York e Longden (2004), as possibilidades de sucesso abarcam três dimensões: sistema educacional, instituição e alunos.

No que diz respeito ao sistema educacional: valorizar a indissociabilidade entre ensino e pesquisa; oferecer bolsa de estudos; elaborar um sistema de certificação contínua; fornecer subsídios financeiros para ensino, pesquisa e extensão; estimular a formação continuada dos professores no Brasil e no exterior.

Quanto à instituição: podem ser alocados mais recursos para o $1^{\circ}$ ano do curso, já que é aí que se concentra o maior número de evasões; lembrar-se de que se há de atender a um público-alvo diversificado (idades, etnia, gênero, necessidades especiais, etc.), o que exige que se disponibilizem as informações em linguagem e formato adequado; desenvolver programas de inclusão social; utilizar o design universal para atender às necessidades especiais; fornecer feedbacks personalizados; proporcionar suporte 24 horas para atividades síncronas e assíncronas; proporcionar cursos de atualização que propiciem suporte aos professores; empregar avaliação diagnóstica e formativa além da tradicional somativa.

No que se refere aos alunos: há necessidade de diferentes tipos de orientação: escolha do curso; evitar escolha de última hora; planejar as atividades; adotar o objetivo de aprendizagem e não, exclusivamente, o de desempenho. No entanto, conforme ensina Palácios (1995), tanto na comunidade convencional como na comunidade virtual estão presentes 
Perfil e avaliação dos participantes de um curso de formação continuada em práticas...

alguns elementos básicos de uma comunidade do tipo ideal que facilitam a permanência dos estudantes no curso, entre elas destacam-se: o sentimento de pertencimento; a territorialidade, real ou simbólica; a permanência; a cooperatividade entre os membros da comunidade; a existência de um projeto único; e a forma de comunicação entre os participantes.

Assim sendo, embora não ocorra a dialogicidade presencial, esses elementos básicos favorecem o processo de ensino-aprendizagem.

Neste estudo, a ênfase recaiu em professores do Ensino Fundamental, que, dentro do sistema educacional, têm poucas oportunidades formais de atualização ou aprendizado de novos conteúdos, como, por exemplo, as Práticas Pedagógicas em Educação Especial e Inclusiva: eixo temático do curso.

Assim, para esta pesquisa, estabeleceram-se três objetivos: 1- descrever o perfil dos participantes do curso ofertado, quanto à sua formação inicial e continuada, idade, gênero e localidade; 2- analisar a avaliação do curso realizada pelos alunos; 3- analisar os motivos que levaram parte deles a desistir do referido curso.

Nessa perspectiva, estruturou-se este texto em três partes: 1- A EaD, relacionada com o contexto, a condução e o conteúdo do curso pesquisado; 2- Trajetória metodológica, em que são descritos os participantes, instrumentos utilizados e procedimentos de coleta e análise dos dados; 3- Resultados e discussão.

\section{A Educação a Distância}

A Educação a Distância é uma prática educativa, processo de ensino-aprendizagem que conduz o indivíduo a "aprender a aprender", a saber, a pensar, a criar, a inovar, a construir conhecimentos, ou seja, a participar ativamente de seu próprio crescimento. Dependendo da concepção epistemológica, das tecnologias de suporte e da abordagem pedagógica, os programas de EaD podem ter o nível de diálogo priorizado ou não. Peraya (2002, p. 49) ensina que a utilização de determinada tecnologia como suporte à EaD "não constitui em si uma revolução metodológica, mas reconfigura o campo do possível".

Entende-se que o uso das Tecnologias de Informação e Comunicação (TIC) engendra a produção de conhecimento individual e grupal em processos colaborativos, favorecidos, neste estudo, pelo uso do TelEduc, que permite ruptura entre as distâncias espaço-temporais e viabiliza recursividade, múltiplas interferências, conexões e trajetórias, não se restringindo à simples transmissão de informações e tarefas definidas a priori. Conforme Barros et al. (2007, p. 5, grifos dos autores),
[...] O objetivo do Ambiente é proporcionar a dinamização das disciplinas, a colaboração e interação entre elas e sua contextualização no processo de aprendizagem, favorecendo a comunicação entre professor/aluno, aluno/professor e aluno/aluno. Nesse Ambiente, portanto, as pessoas que buscam novos conhecimentos, podem se comunicar e interagir com colegas e orientadores, compartilhar informações, trocar idéias, participar de discussões temáticas em fóruns, desenvolver projetos em grupo, divulgar produção, pesquisar, tirar dúvidas, ser, enfim, o próprio construtor do seu saber em colaboração com seus pares.

Moraes (1997, p. 68) reforça que, ao se conceber a EaD dessa forma, instaura-se um sistema aberto, "com mecanismos de participação e descentralização flexíveis, com regras de controle discutidas pela comunidade e decisões tomadas por grupos interdisciplinares". Trata-se, portanto, de processo de humanização, que alcança fatores pessoais e estruturais, em que se parte da situação concreta em que se dá a ação educativa numa relação dialógica e reflexiva entre os personagens envolvidos. Belloni (1999) complementa essas considerações enfatizando que a Educação a Distância pode ser concretizada de diferentes maneiras. Todavia, o ponto comum entre elas é a separação entre professor e alunos em que a mediação é realizada pela instrumentalização da ferramenta tecnológica. Há, também, a presença de tutoria, cujo papel é esclarecer dúvidas. Porém, como na educação presencial, as interações são bidirecionais, planejadas, considerando-se o processo de ensino-aprendizagem fundamentado em métodos científicos.

O aluno da Educação a Distância precisa ter postura própria e atender a demandas diferenciadas, pois ele não deve atuar como receptor passivo de mensagens, mas sim como aluno autônomo, que se desenvolve a partir de seu ritmo. Para isso, necessita de muito mais atenção por parte do tutor, estímulo e incentivos mediante e-mail, chat, enfim, qualquer um dos recursos da tecnologia que possibilite a comunicação com o seu formador. Além disso, a motivação também parte das orientações sobre a forma de uso do material, que devem ser claras e precisas, daí a ênfase no papel do professor quanto à preparação do mesmo. (NISKIER, 1999).

Nesse sentido, o tutor exerce um papel bastante relevante, uma vez que é ele o elo entre os estudantes e os outros profissionais envolvidos no processo de gestão, acompanhamento e avaliação dos programas, o que lhe impõe aprimoramento e fortalecimento permanente desse elo, sem o qual o processo de ensino-aprendizagem ocorre precariamente. De acordo com Ghiraldelli Jr. (2000, p. 24), "é preciso haver um relacionamento erótico permanente entre professor e estudantes". Esse relacionamento sedutor se aprofunda à medida que o contato 
via internet passa a ser mais frequente. Meira (1999, p. 132) também esclarece que

Diante de tão grande número de ofertas visuais, performáticas e espetaculares na sociedade, a escola encontra-se em desvantagem, pois os chamados auxiliares de ensino audiovisual, a comunicação corporal do professor, sua retórica, não convencem. O mundo da escola é um mundo cinza, parado e passivo. As imagens, na escola, são manipuladas como se fossem neutras e inofensivas, além de serem mal aproveitadas em termos de possibilidade educativa. Não se prepara o professor para desempenhos comunicativos e expressivos em nível do desafio do ensino e das crianças atuais, não se prepara o professor, sobretudo, para dialogar com o mundo através de um universo imaginal.

Gutierrez e Prieto (1994, p. 62), enfatizando a noção de mediação pedagógica, destacam, ainda, que se trata de "tratamento de conteúdos e das formas de expressão dos diferentes temas, a fim de tornar possível o ato educativo dentro do horizonte de uma educação concebida como participação, criatividade, expressividade e relacionalidade". Ressaltam, ainda, que no ensino presencial essa mediação ocorre em sala de aula e depende quase sempre da capacidade e da paixão do professor, mas também pode ocorrer em sistemas a distância. Nesse caso, afirmam os autores: "são os materiais que encarnam essa paixão; são eles que permitem ao estudante encontrar e concretizar o sentido do processo educativo." (GUTIERREZ; PRIETO, 1994, p. 9).

Além disso, outro aspecto importante a ser considerado é o fator tempo. Enquanto a dimensão do espaço pode ser resolvida com a oferta de materiais interativos e/ou uso de tecnologias como o fax, o e-mail e o chat, que facilitam a comunicação entre professor e aprendentes, a questão do tempo é mais complexa, uma vez que possui, em seu interior, dimensões e aspectos que interferem no processo educativo. (TOSCHI, 2000).

O tempo é fundamental no EaD, não apenas em suas dimensões física, institucional e imaginária, que formam a base das relações temporais concebidas pelos indivíduos e estabelecidas na sociedade, mas também em sua dimensão econômica, de medida do tempo de trabalho, das suas condições e de formação dos trabalhadores. A ausência de um tempo para a formação continuada, previsto especificamente para esse fim, dentro da jornada de trabalho dos professores, é, provavelmente, a causa principal da baixa efetividade de programas dessa natureza.

Considerando os aspectos apontados, ainda é necessário compreender melhor o fenômeno em estudo: a questão fundamental não está tanto na modalidade do ensino oferecido - presencial ou a distância. A convergência dos dois paradigmas constitui-se na tendência mais evidente, porém, sobretudo, na capacidade de os sistemas educacionais inovarem quanto aos conteúdos e às metodologias de ensino, de refletirem sobre novas soluções para os problemas antigos e também para os recentes, oriundos dessa nova demanda - ou seja, gerados pelo avanço tecnológico nos processos de informação e comunicação, especialmente aqueles relacionados com as novas formas de aprender. (PERRIAULT, 1996; CARMO, 1998).

Nessa perspectiva, a melhor forma de compreender um fenômeno de ensino após sua ocorrência é ter espaço e estratégias para avaliar os resultados obtidos. Desenvolver a temática sobre avaliação em EaD é tarefa tão complexa quanto a sua prática, uma vez que abrange diferentes etapas, objetivos e contextos cuja finalidade comum é a qualidade da formação no caso dos educadores.

Para Barros et al. (2008), no transcurso da avaliação o respeito à individualidade é importante, o que implica compreender e valorizar o percurso atravessado pelo aluno durante o processo educacional para atingir suas metas. Trata-se, portanto, de um processo de avaliação contínua, sujeito a negociações e redirecionamentos, visando um melhor aproveitamento do curso pelos estudantes.

\section{O contexto, o conteúdo e a dinâmica do curso pesquisado}

O objetivo geral da equipe proponente foi o de promover o curso de formação continuada Aperfeiçoamento em Práticas em Educação Especial e Inclusiva na área de Deficiência Mental, oferecido a professores de 20 (vinte) turmas inscritas pelo Ministério da Educação, de diferentes regiões do Brasil, com 180 (cento e oitenta) horas de duração, por meio de EaD, que viabilizasse conteúdos teóricooperacionais na área de deficiência intelectual e seus desdobramentos para prestação de serviços em propostas educacionais, com enfoque nas práticas educacionais inclusivas.

Os objetivos específicos do referido curso consistiram em: a) discorrer sobre desenvolvimento humano e aspectos da deficiência intelectual: etiologias, história, legislação, aspectos éticos e conceitos vigentes; b) implementar avaliação de desempenho acadêmico, de desenvolvimento e repertório comportamental; c) planejar estratégias de ensino que acolhessem a diversidade e promovessem o desenvolvimento de todos os alunos.

O curso contou com 12 (doze) disciplinas, que versavam sobre temáticas referentes à área 
de Educação Especial e/ou Educação Inclusiva, objetivando subsidiar as práticas pedagógicas dos cursistas a partir da oferta de respaldo teóricooperacional. A plataforma utilizada nesse curso foi o ambiente TelEduc, por meio do qual os professores interagiram com os tutores e respectivos formadores, enviando e recebendo e-mails, participando de fóruns de discussão, bate-papos, videoconferências e recebendo orientações sobre atividades pertinentes a cada disciplina.

O conteúdo do curso foi trabalhado em cadernos de leituras, subdivididos em unidades temáticas por disciplinas, videoconferências e textos de apoio, colocados periodicamente no ambiente, conforme cronograma pré-divulgado, além de material teórico e atividades práticas. Durante seu desenvolvimento, os tutores orientaram a produção dessas atividades, em que os cursistas as realizavam em seus ambientes de trabalho e as disponibilizavam on-line, o que Ihes permitia reflexão e troca de experiências.

Ainda, quanto ao conteúdo, ressalta-se que Educação Especial e Inclusiva consiste em ação educativa pensada para a diversidade humana, já que, quando se fala em inclusão, não se está remetendo, unicamente, aos indivíduos com necessidades educativas especiais; fala-se, também, de uma prática educativa que considere todos os seres humanos em suas singularidades.

Estou chamando de escola inclusiva não apenas a escola que tem algumas crianças com limitações sensoriais e orgânicas no conjunto dos alunos regulares, porque para mim a educação inclusiva é mais do que termos crianças com limitações ou problemas dessa natureza nas salas de aula convivendo com outras crianças. Significa, também, os professores de Educação Infantil, de Escola Fundamental, de Ensino Médio, o corpo administrativo, os líderes da escola participando de uma mesma atividade e comprometidos com um mesmo projeto educacional. (MACEDO, 2005, p. 17).

A escola inclusiva é, pois, um desafio, posto que proponha mudanças de paradigmas e revisão de valores há muito arraigados aos saberes educacionais. Segundo Aranha (2000, p. 2), "a ideia de inclusão se fundamenta numa filosofia que reconhece e aceita a diversidade, na vida em sociedade". Para a autora, incluir significa garantir o acesso de todos a todas as oportunidades, independentemente das peculiaridades de cada um. Ainda, conforme Oliveira e Leite (2000, p. 11),

A construção de uma Escola Inclusiva deverá ter como pressuposto básico um novo paradigma educacional que preconiza uma Escola para Todos, garantindo a igualdade de oportunidade, independente de qualquer característica individual, incorporando a diversidade existente num país multicultural como o Brasil e nos remetendo a uma nova forma de conceber o papel da escola e o próprio conceito de deficiência.
No que se refere ao atendimento das pessoas com necessidades educativas especiais, Aranha (2000) explicita diferentes paradigmas que regulamentaram as relações entre esses e a sociedade. A Institucionalização foi o primeiro paradigma que defendia a ideia de que a pessoa diferente deveria ser protegida num ambiente segregado. Tal paradigma gerou as internações em instituições nas quais os indivíduos com algum tipo de deficiência passavam toda a sua vida separados do convívio social.

O segundo paradigma, denominado de Serviços, fazia duras críticas à Institucionalização e propunha a integração social das pessoas com deficiência. No entanto, tal integração pressupunha a preparação dessas pessoas para "funcionar" da maneira mais semelhante possível aos demais membros da sociedade. Não se propunha, portanto, mudança social, mas a alteração do indivíduo, que deveria se esforçar para se adaptar e levar uma vida o mais próxima possível da "normalidade".

A partir de discussões sobre a importância das intervenções com objetivos educacionais, terapêuticos, de habilitação e reabilitação de pessoas com necessidades educativas especiais, surge o terceiro paradigma, denominado Suportes, que defende a ideia de inclusão e de convivência na diversidade, baseado no princípio da igualdade.

Tal compreensão traz implicações sérias, já que garantir o referido acesso vai exigir providências bidirecionais: além das costumeiras ações de intervenção direta junto aos sujeitos com necessidades especiais, faz-se necessário desenvolver ações junto à sociedade, que deve se ajustar para a convivência na diversidade. (ARANHA, 2000, p. 4).

Então, este foi o paradigma empregado ao longo do curso em questão.

Este curso foi desenvolvido por uma equipe de professores, composta por um coordenador, um supervisor de $\mathrm{EaD}$ e cinco pesquisadores. Tais profissionais são docentes, provenientes de dois cursos de graduação da Faculdade de Ciências, UNESP/ Bauru: Educação e Psicologia que, também, em sua maioria, são docentes do Programa de Pós-Graduação em Psicologia do Desenvolvimento e Aprendizagem (mestrado acadêmico) da referida faculdade. O conjunto de docentes foi interessante não só para o meio acadêmico, mas, principalmente, para o contexto social, uma vez que o alcance da proposta foi além dos muros da universidade, atendendo às demandas que fluem, no dia-a-dia, das populações carentes, no âmbito educacional, no intuito de se promover o desenvolvimento humano.

Além da equipe que o elaborou, foi necessária a colaboração de um grupo de profissionais, constituído de formadores e tutores, para auxiliar no desenvolvimento teórico-operacional do curso. Os 
formadores se constituíram num grupo de 10 (dez) professores, com titulação de doutorado ou mestrado em áreas afins, que auxiliaram na produção do material impresso e eletrônico e acompanharam o desenvolvimento dos alunos do curso por meio do ambiente midiático.

Já a equipe de tutores era formada por 20 (vinte) profissionais, com titulação mínima de curso superior em área correlata ao curso, com no mínimo um ano de experiência docente, além de alunos de pós-graduação. Sua função era operacionalizar o curso na plataforma midiática, acompanhando todas as atividades desenvolvidas pelos professorescursistas.

O tutor e o professor formador, com o auxílio dos professores pesquisadores responsáveis pelos conteúdos das disciplinas e das atividades propostas, acompanharam o desempenho dos cursistas durante todo o processo. Caso o desempenho na tarefa não atingisse plenamente os objetivos, o cursista recebia orientação sobre como poderia melhorá-la, permitindo que a refizesse até que obtivesse sucesso. Este movimento aconteceu sempre que foi necessário ou possível em todas as disciplinas. O critério estabelecido, ao final do curso, foi o cumprimento de $70 \%$ das atividades propostas.

\section{Trajetória metodológica}

\section{Participantes}

Preencheram o perfil 413 dos 503 alunos matriculados. Desses, responderam ao instrumento de avaliação do curso 352 cursistas que concluíram o curso e a amostra dos desistentes contou com 42 participantes.

\section{Procedimentos para a coleta de dados}

Os dados sobre o primeiro objetivo - descrição do perfil dos participantes - foram obtidos por intermédio de consulta às informações disponibilizadas pelos próprios professores cursistas, no ambiente do curso.

Já para o segundo objetivo - avaliação do curso -, ao seu final foi aplicado um questionário, com questões fechadas, a ser respondido em uma escala com opção de respostas de seis valores múltiplos (concordo fortemente, concordo, incerto, discordo, discordo fortemente, não se aplica).

Para o alcance do terceiro objetivo - motivos da evasão - foi elaborado um questionário com questões abertas, visando identificar as razões da desistência. Para tanto, utilizou-se um questionário composto por 11 (onze) questões sobre possíveis motivos que pudessem elucidar a evasão dos participantes: motivos pessoais; expectativas com relação ao curso; realização de curso on-line; dificuldades com o computador; dificuldades com o material do curso; dificuldades com as atividades propostas nas disciplinas; tempo para realizar as atividades de cada disciplina; feedback das avaliações nas tarefas realizadas; apoio técnico disponível na cidade de origem (por exemplo: Secretaria de Educação). O questionário também foi enviado por e-mail aos 90 (noventa) alunos evadidos, acompanhado por uma carta dizendo da importância da colaboração deles para possíveis alterações na proposta do curso na busca de adequações e melhorias. Estabeleceu-se prazo para a resposta e, ao seu final, alcançou-se um total 42 participantes.

\section{Procedimento para análise dos dados}

Para análise e interpretação dos dados, escoIheu-se a perspectiva quanti-qualitativa, em que se procura sempre apresentar a visão dos participantes. A análise quantitativa, seguindo-se os postulados de Barbetta (2009), delineia certas características específicas da população, entendida como um conjunto de elementos passíveis de serem mensurados, com respeito às categorias recorrentes que se apresentam na análise dos dados. Para se medir esse conjunto, empregou-se como estimador a porcentagem.

Quanto aos aspectos qualitativos, Lüdke e André (1986) explicitam que a pesquisa qualitativa tem como sua fonte direta o ambiente natural e como as coisas acontecem na realidade. Ainda, de acordo com Oliveira (2005), trata-se de um processo de reflexão sobre a realidade e sua análise, na qual os métodos e as técnicas utilizadas buscam a compreensão detalhada do objeto a ser estudado no seu contexto sócio-histórico, pois, nessa abordagem, todos os fatos e fenômenos observados são significativos e relevantes. Essas autoras destacam, também, que a pesquisa qualitativa permite interpretação bastante profunda das particularidades, atitudes e comportamentos dos sujeitos envolvidos, possibilita a descrição detalhada ou o relato pormenorizado sobre o assunto pesquisado e, por fim, propicia condições para se estabelecer correlações que direcionam o ponto de vista conclusivo. A análise de dados foi, então, realizada de duas formas:

a) quantitativamente para perguntas fechadas sobre a formação inicial e continuada, idade, gênero e localidade dos cursistas, assim como para as perguntas do $1^{\circ}$ questionário, em que foram apresentadas seis opções. Segundo Barbetta (2009, p. 36, grifos do autor), 
Nas pesquisas científicas em que se quer conhecer algumas características de uma população, também é muito comum se observar apenas uma amostra de seus elementos e, a partir dos resultados dessa amostra, obter valores aproximados, ou estimativas, para as características populacionais de interesse. Este tipo de pesquisa é usualmente chamado de levantamento por amostragem.

b) qualitativamente para as perguntas abertas do questionário sobre a evasão, a partir das quais foram elencadas as categorias que se apresentaram, fundamentando-se na técnica de Análise de Conteúdo. Bardin (2009) ensina que a Análise de Conteúdo (AC) constitui-se em uma das técnicas de pesquisa para tornar replicáveis e validar inferências ${ }^{11}$ de dados de um contexto que envolve procedimentos especializados para processamentos de dados de forma científica. Seu propósito é prover conhecimento e novos insights obtidos a partir desses dados. Uma parte importante do comportamento, opinião ou ideias de pessoas se exprime sob a forma verbal ou escrita. A Análise de Conteúdo desses dados deve normalmente permitir a obtenção dessas informações resumidas, organizadas. A AC das categorias fez-se por meio do desmembramento das respostas em unidades e seu posterior reagrupamento. Tal técnica procura diminuir o volume de informações dos dados brutos, em categorias que se repetem e não se esgotam em si, devendo ultrapassar a mera descrição, desvelando as mensagens implícitas.

\section{Resultados e discussão}

\section{Perfil dos professores cursistas}

Analisando-se o perfil dos 413 professorescursistas, observa-se que, quanto à origem, 56\% eram do Sudeste, $39 \%$ do Sul e 5\% do Norte do país. Dos participantes, 98\% eram mulheres. Quanto à idade, a maioria, 70\%, tinha entre 31 e 50 anos. Dos demais, $17 \%$ nunca haviam acessado o TelEduc e $13 \%$ não concluíram o curso por motivo de evasão.

Quanto à função que exercem no sistema de ensino, observou-se que 94\% dos cursistas eram professores de ensino regular, sendo que, deles, $7 \%$ eram professores de Educação Especial e 2\% de Educação Física e Educação Infantil, 3\% eram supervisores ou técnicos e os restantes nada relataram.

\footnotetext{
${ }^{1}$ Inferência: "operação lógica, pela qual se aprova uma proposição em verdade de sua ligação com outras proposições já tênues por verdades" (BARDIN, 2009, p. 43). Esse ponto merece especial atenção, porque algumas das expressões têm mais de uma interpretação, ou até mesmo interpretações positivas ou negativas, dependendo do contexto.
}

Sobre formação para a função, 50\% cursaram Pedagogia, 19\% Letras, 19\% não relataram a formação e o restante cursou outras áreas de Licenciatura para docência, como História, Geografia, Matemática, entre outros. Ainda, 2\% relataram estarem cursando Pedagogia, 2\% possuíam somente o Ensino Médio completo e 2\% o Ensino Fundamental completo. A respeito da formação continuada, 61,5\% não relataram esse tipo de curso. Já 38,5\% relataram ter realizado cursos diversos, dos quais os mais frequentes foram Psicopedagogia e Educação Inclusiva.

Em resumo, o perfil dos participantes revela que a maioria dos concluintes foi composta de muIheres (98\%), entre 31 e 50 anos, sendo que 56\% eram da região Sudeste do país. Esse perfil revela, ainda, que $94 \%$ eram professores de ensino regular, dentre os quais 50\% afirmaram ter feito o curso de Pedagogia, sendo que pouco mais da metade não havia feito nenhum curso de formação continuada.

\section{Avaliação do curso pelos participantes}

A análise do desempenho final no curso dos 352 alunos concluintes mostra que $70 \%$ dos participantes concluíram o curso com sucesso. Pôde-se verificar que, desses, 75\% tiveram classificação Ótimo, com notas entre 9,0 e 10,0; 14\%, Bom, com notas entre 8 e 9 , e 11\%, Regular, com nota 7,0.

Para a avaliação do curso, os participantes responderam às seguintes questões: Estou satisfeita/o com o curso? O curso oportunizou adquirir e construir novos conhecimentos? O curso cumpriu o objetivo de formação continuada em Educação Especial na área específica ofertada? Atuaria novamente em um curso a distância oferecido pelo MEC/SEESP e por esta Universidade? O curso cumpriu o objetivo da função social de promover a inclusão?

Dentre os respondentes, $79 \%$ a $82 \%$ fizeram uma boa avaliação geral do curso, afirmando que "concordavam" ou que "concordavam plenamente" com os aspectos discriminados nas questões.

Pode-se então aquilatar, com base em Valente (2003), que o fato de o curso ter sido ministrado a distância, e não presencialmente, pouco interferiu na apropriação das informações trabalhadas, pois o professor formador não agiu como simples "entregador" dos conteúdos, mas sim como facilitador da aprendizagem. Entende-se, também, com Gutierrez e Prieto (1994), que por suas especificidades a EaD exige dos alunos muita disciplina, além da já citada autonomia, que se destina mais propriamente a pessoas adultas e parece ser mais efetiva quanto mais elevado for o seu nível educacional. 
A avaliação do ambiente de ensino revelou que os participantes ficaram satisfeitos em relação à facilidade de aprendizagem e à navegação on-line, uma vez que o ambiente apresentou recursos acessíveis e proporcionou a aprendizagem colaborativa e a integração com os colegas. Deles, 93\% avaliaram o ambiente de ensino como muito bom.

Quanto a esse aspecto, concorda-se com Belloni (1999) quando o autor destaca a mediação do tutor como fundamental para auxiliar no uso da ferramenta tecnológica, pois sempre surgem dúvidas as quais nem sempre o cursista é capaz de solucionar sozinho, o que pode acarretar desânimo e desistência de continuidade.

Em relação ao item "Coordenação Pedagógica do Curso", esse foi avaliado como muito bom por $88 \%$ a $92 \%$ dos participantes, que responderam às seguintes questões: Atendeu prontamente quando solicitado? Apresentou solução para os problemas? Orientou de modo satisfatório?

É possível dizer que a equipe organizadora do curso constituiu-se de um grupo com larga experiência em Educação e, portanto, focado na relação indissociável entre teoria e prática e entre ensino e aprendizagem. Em se tratando de curso a distância, tornou-se ainda maior a preocupação com a efetiva aprendizagem dos participantes, uma vez que nessa modalidade de educação não há a oportunidade da dialogicidade presencial.

Como um dos resultados marcantes, os dados circunscritos por esta pesquisa indicaram que as dificuldades mais frequentes enfrentadas pelos participantes foram o não cumprimento do prazo estabelecido para o envio das atividades realizadas e, consequentemente, a avaliação, por eles próprios, de que o tempo para a realização das tarefas foi insuficiente. Nesse resultado, aprende-se com Toschi (2000) que o uso do tempo não pode ser negligenciado. Dentre os entraves que se apresentam aos cursistas em formação continuada, esse é - senão o maior empecilho - pelo menos o mais crucial, ainda mais quando se tem como professores-cursistas os que trabalham no Ensino Fundamental, caso da maior parte dos integrantes desse curso.

\section{Motivos da evasão}

Participaram desta fase da pesquisa 42 (47\%) cursistas que não concluíram o referido curso. Das questões propostas, o motivo mais frequente foi o "não cumprimento dos prazos para a conclusão das atividades" para $54,7 \%$ dos não concluintes. Outros motivos apresentados foram: "tempo insuficiente para realização das atividades" (47,6\%); "motivos pessoais" (42,8\%); "inabilidade no manuseio do computador e do sistema on-line" (40,5\%) e "excesso de atividades" (35,7\%).

Quando os participantes foram questionados a respeito do apoio recebido em suas cidades de origem, 16,6\% avaliaram que a frequência foi abaixo do desejado. No que se refere ao "descontentamento com os conteúdos das disciplinas oferecidas e atividades propostas", o valor atingido foi de 4,6\%, enquanto se "o curso desapontou as expectativas pessoais" o percentual foi de $2,3 \%$.

Belloni (2002) alerta quanto a esse aspecto técnico dos cursos de $\mathrm{EaD}$, afirmando que os problemas não estão localizados sempre em relação ao ensino, mas também do lado da demanda. Essa população-alvo não tem, provavelmente, história de autoestudo, o que pode gerar desânimo e falta de iniciativa para vencer os obstáculos. Tudo isso se agrava quando esses participantes assinalam que motivos pessoais estão em terceiro lugar no que se refere a impedimento de conclusão do curso.

Quando o aluno se depara com falta de controle da sua rotina e precisa realizar atividades adicionais, com um nível de complexidade acentuada, seu perfil para compor o quadro de discente de um curso EaD não alcança o mínimo necessário, como tem sido a proposta de pesquisadores da área. Defendem-se, aqui, os postulados de Barros et al. (2008) e de Valente (2003), quando afirmam que esse estudante deve ser extremamente dinâmico e ágil na construção de conhecimentos, fato não alcançável nessa realidade devido à grande dependência dos discentes e de seus tutores para a realização das atividades on-line.

Como que num encadear de ideias, encaixam-se os próximos itens mais frequentes como impedimentos para o sucesso dos alunos evadidos, ou seja, dificuldade no manuseio do computador, assim como no acesso a ele. Também ficou demarcada a dificuldade ao lidar com o sistema on-line e, por toda a morosidade que tal demanda gerou, o tempo tornou-se insuficiente para a realização das tarefas.

Concorda-se com Niskier (1999) que uma das vantagens do curso pelo sistema on-line é ter à disposição a ferramenta dos e-mails para constantemente incentivar os alunos, mas, no contexto deste estudo, considerando as diferenças entre eles (BELLONI, 2001a; CANCLINI, 1998), os e-mails em muitos casos tinham a função apenas de auxiliar o aluno a vencer o receio de lidar com a "máquina".

Reforçando-se o que ensina Ghiraldelli Jr (2000), a comunicação é essencial ao processo de ensino-aprendizagem desde que seja afetiva, gerando confiança e valendo-se dos meios adequados para contribuir diretamente à motivação dos alunos. 
Outro aspecto a considerar no que se refere ao uso do sistema on-line é que ele minimiza a questão espaço, mas nem sempre o tempo (TOS$\mathrm{CHI}, 2000$ ), fato que se torna comprometedor para aqueles que não têm familiaridade com esse tipo de sistema, nem com toda a tecnologia envolvida, demandando maior número de horas na realização das atividades quando comparados aos alunos hábeis em realizá-las.

Diante de tais constatações, salta aos olhos que encarar toda a extensão do território nacional como uniforme pode ser um problema sério para a eficiência do curso. Ficou evidente que é necessário uma fase de preparo técnico-funcional, de forma diferenciada para as populações das diferentes localidades do país.

Apesar de o número de participantes deste estudo ser reduzido, a análise e a discussão dos resultados encontrados corroboram a literatura aqui apresentada (BELLONI, 2001b; CANCLINI, 1998) quando o foco dos resultados concentra-se nos aspectos funcionais do curso.

No que se refere ao conteúdo, pode-se afirmar que a baixa porcentagem da adesão dos professores-cursistas, quando questionados "se o curso não correspondeu às suas expectativas", assim como "se as disciplinas e as atividades não foram adequadas e positivas", gera a certeza de que, vencendo a barreira técnica, os conteúdos trabalhados são suficientes para que o fenômeno da Educação a Distância aconteça, contribuindo como parte de um processo de inovação educacional. (BELLONI, 2001a; CARMO, 1998; PERRIAULT, 1996).

Assim, o conteúdo não é o problema central, já que o manuseio do computador e do sistema on-line despontou como o maior motivo das dificuldades encontradas pelos participantes do estudo. Deduz-se que o fazer chegar as informações claras e objetivas no que se refere aos aspectos técnicos do curso, antes do seu início propriamente dito, é de vital importância para seu sucesso e, consequentemente, para o controle de evasão da população envolvida. Também não se pode realizar análise simplista dos resultados evidenciados neste estudo, descolados da macroestrutura sócio-político-econômica que engendra o dia-a-dia desses profissionais da Educação: a jornada de trabalho, o acúmulo de afazeres domésticos das mulheres (maioria dos cursistas) em função de baixo poder aquisitivo, pouca familiaridade com estudos em rede, com o uso da tecnologia, aliados ao descaso da política educacional brasileira - que pouco incentiva e reconhece o trabalho docente - agravam este quadro.

\section{Considerações finais}

Acredita-se que o curso de Aperfeiçoamento em Práticas em Educação Especial e Inclusiva na área da Deficiência Mental, ofertado na modalidade de $\mathrm{EaD}$, tenha atingido os objetivos propostos para a maioria dos professores participantes, tantos nos aspectos metodológicos quanto nos teóricos, favorecendo assim a formação continuada dos aprovados. Com isso, espera-se que as unidades escolares, por meio da atuação profissional desses professores, tenham maiores condições de proporcionar práticas pedagógicas realmente inclusivas.

A positividade desse curso na modalidade de EaD pode, então, ser declarada em função de se ter atingido a um número significativo de professores de várias localidades do Brasil ao mesmo tempo, o que pode permitir que coloquem em prática os conhecimentos teórico-práticos de que se apropriaram de maneira mais ou menos uniforme, favorecendo o tratamento igualitário dos alunos com necessidades especiais.

Ressalta-se, ainda, que a EaD se mostrou como uma ferramenta relevante de formação continuada do professor-cursista, destacando-se que a participação em cursos dessa natureza também propicia a aquisição de conhecimentos importantes para sua prática pedagógica.

Pôde-se constatar, assim, que esse sistema de ensino inova na medida em que seu impacto educativo, como regra, provém da ambiência humana imbricada no processo formativo, em que se deve dar mais importância à Educação em si mesma e não ao fato de ela ocorrer por via tecnológica.

No entanto, considera-se que esta modalidade de educação requeira a realização de pesquisas diversas para que possa ser aprimorada sua utilização em larga escala, principalmente quando se analisa o perfil diversificado do público-alvo. Seria necessário, por exemplo, oferecer primeiramente - pelo menos nas localidades de nível socioeconômico e cultural relativamente baixo - um curso teórico-prático sobre uso das ferramentas tecnológicas.

Além disso, percebe-se a necessidade de se trabalhar inicialmente com os estudantes a questão da administração do tempo - conforme evidenciado como um dos resultados mais marcantes da avaliação sobre a efetividade do curso. Embora ainda não haja amparo legal para se prever no calendário anual um horário fixo para estudos e formação continuada, cabe ao professor preocupar-se com seu crescimento pessoal e profissional.

Administrar o tempo é administrar a própria vida; há que se saber estabelecer prioridades, mesmo estando inseridos neste modelo de capitalismo 
tardio em que se vive atualmente, que propaga que todos os indivíduos tenham que "se adaptar" às exigências do mercado. Esse é, dentre outros, um aspecto primordial a ser trabalhado em sala de aula quando se prega a indissociabilidade entre Educação e Política.

Ainda, o ambiente de Educação a Distância não pode ser encarado como simples ferramenta que disponibiliza leituras para o aluno, que por sua vez realiza as atividades para esperar, no final, se foi aprovado ou não. A EaD é uma forte tendência quando se pensa em oferecer cursos de formação para grande número de estudantes, em virtude da diversidade de formação de profissionais presentes em nosso país. E, para a realização dessa modalidade, percebe-se que o TelEduc consegue atuar como eficiente ambiente de suporte educacional.

Salienta-se que o TelEduc atinge essa eficiência devido ao fato de o professor, na maior parte do tempo, não "lecionar", centrando-se, em vez disso, em acompanhar, gerenciar, supervisionar e avaliar o que está acontecendo ao longo do curso. O papel do professor muda claramente: orienta mais do que explica. Ademais, a avaliação caracteriza-se pelo uso diversificado de instrumentos, podendo combinar momentos de avaliação do conteúdo e do processo, das atividades individuais e grupais, da construção individual (pesquisa, portfólio) com a coletiva.

Por fim, quando se pensa que a Educação Inclusiva já se tornou realidade no cotidiano das escolas brasileiras, amparada pelas políticas públicas atuais, considera-se que o curso proposto, a partir dos relatos dos professores-cursistas concluintes, conseguiu proporcionar condições de reflexão e discussão sobre práticas pedagógicas voltadas para a promoção de uma escola que atenda, realmente, a todos os alunos de forma igualitária.

Entretanto, com as reflexões pontuadas sobre os percalços técnico-operacionais vivenciados no desenvolvimento do curso, ressalta-se que Educação é um fenômeno da História e o viver implica as duas, intrinsecamente ligadas, uma vez que, ou Educação e História se expandem, ou a decadência de ambas ocorre concomitantemente: aspecto a ser discutido em outras pesquisas.

\section{Referências}

ARANHA, M. S. F. A inclusão social e a municipalização. In: MANZINI, E. J. (Org.). Educação especial: temas atuais. Marília: UNESP - Marília Publicações, 2000. p. 1- 9.

BARBETTA, P. A. Estatística aplicada às ciências sociais. 9. ed. Florianópolis: Editora da UFSC, 2009.
BARDIN, L. Análise de conteúdo. Ed. rev. e aum. Lisboa: Edições 70, 2009.

BARROS, D. M. V. et al. Educação a distância: desafios atuais. Caderno 1. Programa de formação continuada de professores na educação especial. Bauru: MEC/FC/SEE, 2007.

Educação a distância: desafios atuais. In: CAPELLINI, V. L. M. F.; RODRIGUES, O. M. P. R (Orgs.). Práticas em educação especial e inclusiva na área da deficiência mental. Bauru: MEC/FC/SEE, 2008. v. 1. p. 4-33.

BELLONI, M. L. Educação à distância. Campinas: Autores Associados, 1999.

O que é mídia-educação. Campinas: Autores Associados, 2001a (Coleção Polêmicas do Nosso Tempo, 78).

- Integração das tecnologias de informação e comunicação aos processos educacionais. In: BARRETO, R. G. (Org.). Tecnologias educacionais e educação a distância: avaliando políticas e práticas. Rio de Janeiro: Quartet, 2001b. p. 37-69.

Ensaio sobre a educação a distância no Brasil. Educação \& Sociedade, Campinas, v. 23, n. 78, p. 117-142, abr. 2002.

DOI: $10.1590 / S 0101-73302002000200008$

CANCLINI, N. G. Culturas híbridas: tragédias para entrar e sair da modernidade. São Paulo: EDUSP, 1998.

CARMO, H. Ensino superior à distância. Lisboa: Universidade Aberta, 1998

COELHO, M. L. A evasão nos cursos de formação continuada de professores universitários na modalidade de educação a distância via internet. Belo Horizonte: Editora da UFMG, 2002.

FIDALGO, F.; MACHADO, L. Dicionário da educação profissional. Belo Horizonte: Núcleo de Estudos sobre o Trabalho e Educação, 2000.

FROMM NETTO, S. Telas que ensinam: mídia e aprendizagem do cinema ao computador. Campinas: Alínea, 1998.

GHIRALDELLI JUNIOR, P. Didática e teorias educacionais. Rio de Janeiro: DP\&A, 2000.

GUTIERREZ, F.; PRIETO D. A mediação pedagógica: educação à distância alternativa. Campinas: Papirus, 1994.

LUDKE, M.; ANDRÉ, M. E. D. A. Pesquisa em educação: abordagens qualitativas. São Paulo: EPU, 1986.

MACEDO, L. Ensaios pedagógicos: como construir uma escola para todos? Porto Alegre: Artmed, 2005.

MEIRA, M. Educação estética, arte e cultura do cotidiano. In: PILLAR, A. D. (Org.). A educação do olhar. Porto Alegre: Mediação, 1999. p. 119-140.

MORAES, M. C. O paradigma educacional emergente. Campinas: Papirus, 1997. 
NISKIER, A. A educação a distância: a tecnologia da esperança. São Paulo: Loyola, 1999.

OLIVEIRA, A. A. S.; LEITE, L. P. Escola inclusiva e as necessidades educacionais especiais. In: MANZINI, E. J. Educação especial: temas atuais. Marília: Unesp: Marília Publicações, 2000, p. 11-20.

OLIVEIRA, M. M. Como fazer pesquisa qualitativa Recife: Ed. Bagaço, 2005.

PALACIOS, M. O medo do vazio: comunicação, sociabilidade e novas tribos. In: RUBIM, A. A. C. (Org.). Idade Mídia. Salvador: EDUFBA, 1995. p. 88-106.

PERRIAULT, J. La communication du savior a distance. Paris: Hachette, 1996.

PERAYA, D. O ciberespaço: um dispositivo de comunicação e de formação midiatizada. In: ALAVA, S. Ciberespaço e formações abertas: rumo a novas práticas educacionais? Porto Alegre: Artmed, 2002. p. 25-52.

SHANNON, G.; BYLSMA, P. Helping students finish school: why students drop out and how to help them graduate. Office of Superintendent of Public Instruction, Olympia, WA, 2006.

TOSCHI, F. Formação de professores e tv escola. In: REUNIÃO ANUAL DA ASSOCIAÇÃO NACIONAL DE PÓS-GRADUAÇÃO E PESQUISA EM EDUCAÇÃO, 13., 2000, Caxambu. Anais... Caxambu: ANPEd, 2000.

VALENTE, J. A. Educação a distância no ensino superior: soluções e flexibilizações. Interface - Comunicação, Saúde, Educação, Botucatu, v. 7, n. 12, p. 139-148, fev. 2003. DOI: 10.1590/S1414-32832003000100010

YORK, M.; LONGDEN, B. Retention and student success in higher education. Buckingham: Open University Press, 2004.

WORKMAN, J. J.; STERNARD, R. A. Student support services for distance learners. Deosnews, v. 6, n. 3, 1996. Disponível em: <http://www.ed.psu.edu/acsde/ deos/deosnews/deosnews6_3.asp>. Acesso em: 2 dez. 2010.

Recebido em 05/04/2010

Versão final recebida em 29/07/2010

Aceito em 29/09/2010 